\title{
INFLUENCE OF TOTAL NECK LENGTH AND ANTEROPOSTERIOR DIAMETER OF THE HEAD ON TOTAL HEAD EXCURSION - A PROSPECTIVE STUDY
}

\author{
VRINDHA BAROOR ${ }^{1}$, GAYATHRI RAJ ${ }^{2}$, MICHAEL RAJ ${ }^{3}$, DHEERAJ LAMBA ${ }^{3 *}$ \\ ${ }^{1}$ Department of Physiotherapy, Lovely Professional University, Phagwara, Punjab, India. ${ }^{2}$ Lovely Professional University. Phagwara, Punjab, \\ India. ${ }^{3}$ Department of Physiotherapy, Lovely Professional University, Phagwara, Punjab, India. \\ Email: dheeraj.lamba@gmail.com \\ Received: 01 April 2017, Revised and Accepted: 24 April 2017
}

ABSTRACT

Objective: It is estimated that a third of all adults will experience neck pain throughout the course of 1 year, and $70 \%$ is the approximate lifetime prevalence. Neck pain is most commonly reported musculoskeletal pain site in population surveys and primary care. Neck pain can be periodic and can vary in disability. It is important that health-care professionals provide straightforward, clear advice on supervision at an early stage. The purpose of the study was to find variation of total neck length and anteroposterior (AP) diameter of head on total head excursion (THE) which would result in high-risk factor.

Methods: 600 individuals both males and females 8-60 years of age were assigned according to inclusion criteria into three groups and measurement was done through metric ruler scale. Neck length was measured using digital vernier caliper, and AP diameter of the head was measured using spreading caliper.

Results: ANOVA and independent t-test show no significant difference between neck length and AP diameter of head on THE. However, Pearson sig 2-tailed shows a positive correlation with neck length and AP diameter of head on THE.

Conclusion: The findings of the present study states as AP diameter of head decreases, there is decrease in neck length and decrease in retraction and increase in protraction or if there is increase in AP diameter and increase in neck length, there is increase in retraction and decrease in protraction.

Keywords: Neck length, Anteroposterior diameter of head, Posture, Biomechanics.

(C) 2017 The Authors. Published by Innovare Academic Sciences Pvt Ltd. This is an open access article under the CC BY license (http://creativecommons. org/licenses/by/4. 0/) DOI: http://dx.doi.org/10.22159/ajpcr.2017.v10i8.18846

\section{INTRODUCTION}

Anthropometry is a unique and conventional device for physical anthropology which provides scientific method and technique for estimation of a variety of dimensions and interpretation of livelihood and skeleton of a man [1-3]. Assessment of head is important for identification as there is plenty of evidence to find differences among genders. Differentiation of change in cephalic index between parents, children, and siblings can give evidence to genetic transmission of hereditary characters $[4,5]$. Assessment of cervical spine is a difficult task for accurate measurement due to low accuracy of assessment of cervical range of motion as very few landmarks are available and depth of soft tissue overlying the bony segments and mobility influenced by age, biomechanical factors, and pathological development as lateral flexion amplitude is reduced by age and pathology as rotation amplitude is felt majorly in daily life due to inconvenience and amplitude of flexion and extension is present for years [6-12].

\section{Significance of the study}

The outcome of the study will be helpful in providing new information to determine how total neck length (TNL) and anteroposterior (AP) diameter of head on total head excursion (THE) relates to risk for cervical problems in all age groups.

This study will also provide the information to clinicians to determine quick and simple methods for quantitative assessment of TNL, AP diameter of head, resting posture of head and THE and preliminary data on head and neck postural measurements for men and women in all age groups.

\section{METHODS}

Sample size of 600 was taken as per the prevalence and sample size formula and were divided into 3 groups based on age category 200 in each group by stratified sampling technique, and both genders were represented in each group. Data were collected from Lovely Professional University, Uni Hospital, Department of Physiotherapy OPD. Phagwara, Punjab. Outpatient Department of Physiotherapy, Uni Hospital, Lovely Professional University, Phagwara, Punjab, Girls hostels GH-5, 6a and GH-6b, Lovely Professional University, Phagwara, Punjab, Vishwakarma Charitable Hospital, Phagwara, Punjab, Govt. Girls high school, Phagwara, Punjab, Ramgaria Secondary School, Phagwara, Punjab.Villages: Chaheru, Maheru, Nangalmajha, Tanda, Goraya, Hardaspur, Phagwara, Jalandhar, Punjab.

Individuals of the present study were selected based on the following criteria:

\section{Inclusion criteria}

- Age group between 8 and 60 years

- Both male and female

- Both employed and unemployed

- Schoolchildren

- College students

- Normal individual: Neck pain patients (duration less than a month, non-traumatic, non-neurological).

Exclusion criteria

- Neurological deficit - Severe disorders of the cervical spine, such as disc prolapse, spinal stenosis, and lysthesis 
- No prior history of any trauma/surgery

- Uncooperative patients

- Congenital anomalies of the spine

- Neoplasms of spine or brain

- Neurological conditions like epilepsy.

\section{Procedure}

After stratified sampling technique having both genders in each group, the individuals who fulfilled the inclusion criteria was only included in the study and individuals fell in any category of exclusion criteria was excluded from the study. All the individuals were divided into three groups based on age and gender: Group - A, Group - B, and Group - C. Group - A: 200 male and female were included in the age category (8-20 years). Group - B: 200 male and female were included in the age category (21-30 years). Group - C: 200 male and female were included in the age category (36-60 years)

\section{Measurement of TNL}

The individuals were made to sit in a high-backed chair and measurement was taken by palpating the highest point of external occipital protuberance and by marking the prominent $\mathrm{C} 7$ spinous process. This measurement was taken using digital vernier caliper which has the reliability for the above measurement. This measurement was taken using digital vernier caliper (Fig. 1).

\section{Measurement of AP diameter of the head}

The individuals were made to sit in the chair, in a comfortable posture and head was placed in anatomical position and measurement was taken by placing the spreading caliper tip on glabella while the other tip of caliper along the midpoint of the occipital bone until the maximum length was reached. Measurement was taken using blunt ends of the caliper and it was held so that the tips touched the head. Undue pressure was avoided during the measurement. To minimize the errors, all the measurements were taken three times and then, average was taken (Fig. 2).

\section{Measurement of THE}

Measurements were taken while sitting; individuals were asked to sit in a high-backed chair with their foot on the floor, knees hip-width apart, hips, and scapula touching the chair back. The chair was positioned $20 \mathrm{~cm}$ away from the wall. The end of the ruler extending $90^{\circ}$ angle from the wall and rest close to individuals left zygomatic arch. The individual's posture of head was assessed using plumb line and with the ruler at the eye level, marked with pencil, and extended pencil perpendicularly along the ruler. This point is considered as resting head posture (RHP).

Individuals were demonstrated to do complete head excursion from protraction and retraction. Certain instructions were given to the individuals such as to move their heads forward and backward as much as they could maintain their heads straight, do not move their heads up or down, and sideways or turn their heads. Individuals were also asked to warm up for three times, and after that, they were asked to do protraction by moving their head forward, i.e., protraction the point was noted as (P) and were asked to move their heads back this point was noted as (R), i.e., retraction.

The readings were taken three times, and average was noted to minimize any errors while taking the readings. The distance between protraction and retraction represents THE and was measured to the nearest millimeter (Fig. 3).

\section{RESULTS}

Statistics was performed using SPSS 16. After collecting data, descriptive statistics was used to analyze data, and the outcome was displayed as charts and graphs. The results were calculated with 0.05 level of significance.

The results of the study using Pearson correlation sig (2-tailed) show a positive correlation between neck length and AP diameter among all groups and it is statistically significant $(\mathrm{p}=0.006)$.

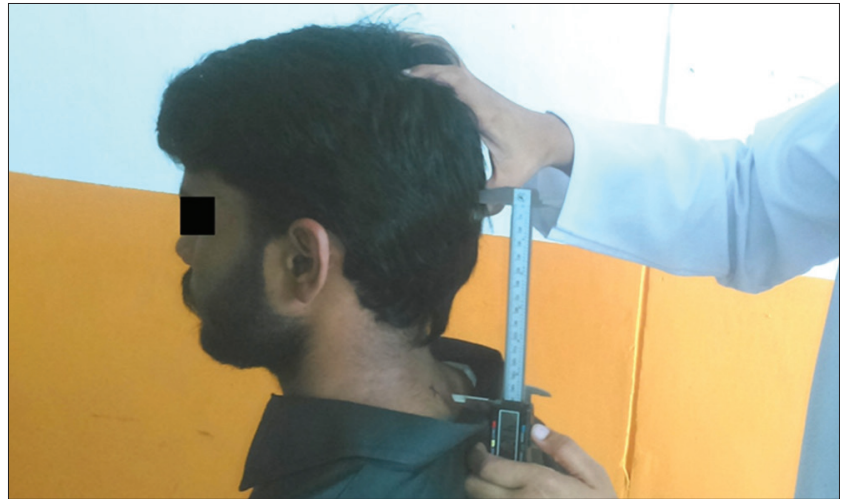

Fig. 1: Measurement of neck length with digital vernier caliper

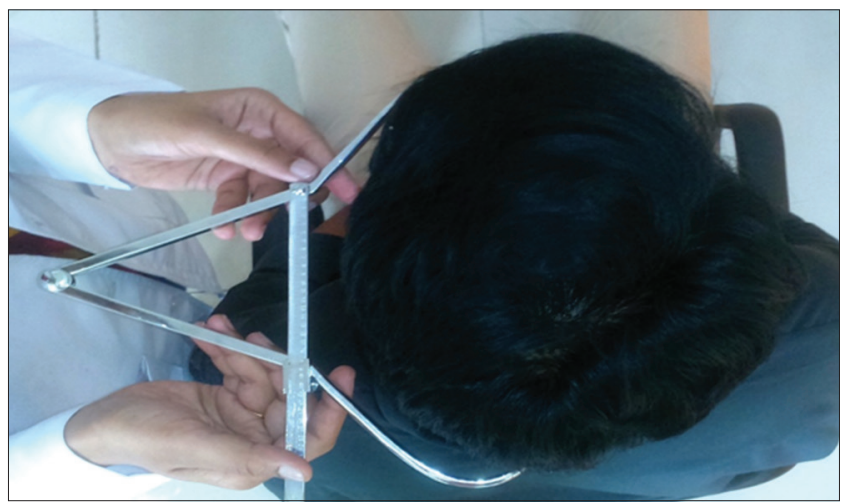

Fig. 2: Measurement of anteroposterior diameter of head with spreading caliper

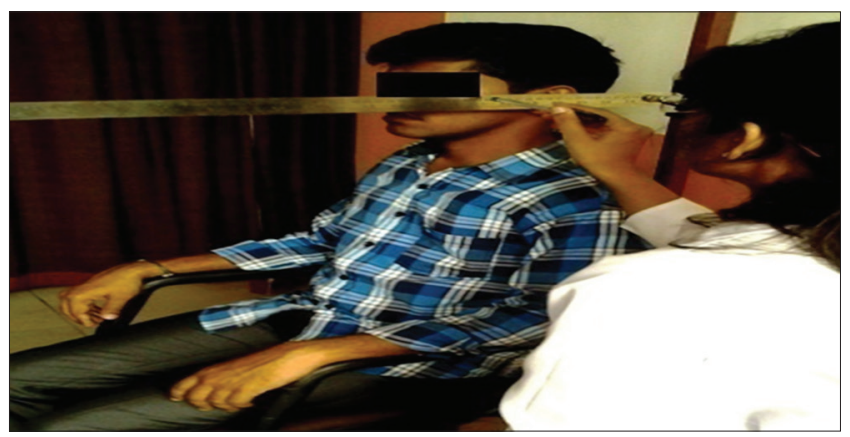

Fig. 3: Measurement of total head excursion with metric ruler scale

Pearson correlation sig (2-tailed) shows a negative correlation between neck length and protraction among all the three groups and it is statistically significant $(\mathrm{p}=0.001)$ (Graph 1$)$.

Pearson correlation sig (2-tailed) shows a positive correlation between neck length and retraction among all the three groups and it is statistically significant ( $\mathrm{p}=0.001$ ) (Graph 2 ).

Pearson correlation sig (2-tailed) shows a negative correlation between AP diameter and protraction among all the three groups and it is statistically significant ( $\mathrm{p}=0.012)$ (Graph 3$)$.

Pearson correlation sig (2-tailed) shows a positive correlation between AP diameter and retraction among all the three groups and it is statistically significant $(\mathrm{p}=0.014)$ (Graph 4$)$.

Pearson correlation sig (2-tailed) shows a negative correlation between Protraction and retraction among all the three groups and it is statistically significant $(\mathrm{p}=0.001)$ (Tables $1-4)$. 


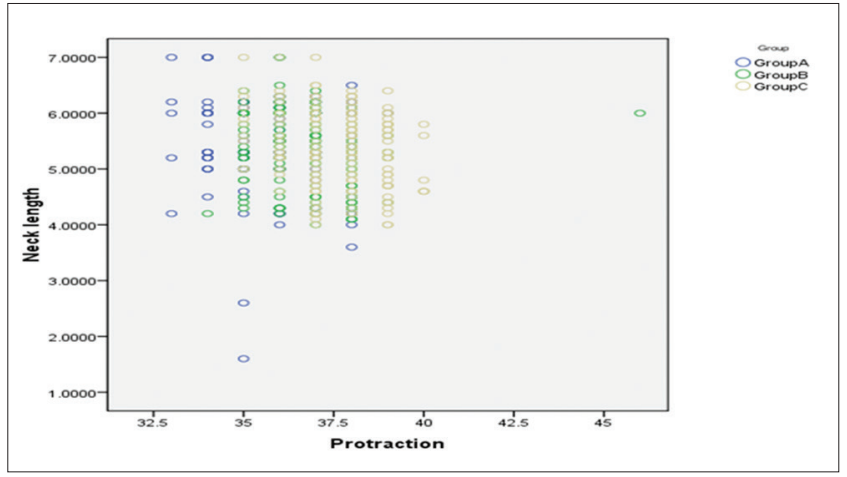

Graph 1: Scatter plot showing Pearson correlation between neck length and protraction

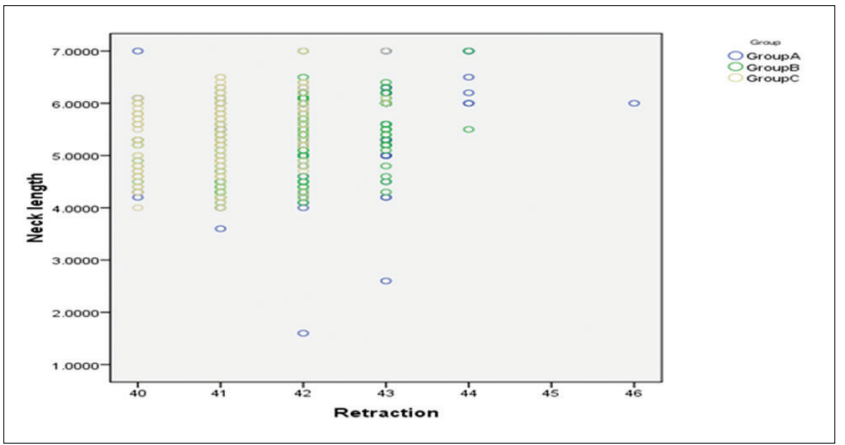

Graph 2: Scatter plot showing Pearson correlation between neck length and retraction

Table 1: Mean and SD values for each outcome measure by gender in Group A

\begin{tabular}{llll}
\hline Parameters & Gender & N & Mean \pm SD \\
\hline Neck length & Female & 103 & $5.526214 \pm 0.6232365$ \\
& Male & 97 & $5.446392 \pm 0.8711895$ \\
AP diameter & Female & 103 & $18.233010 \pm 1.0426576$ \\
& Male & 97 & $18.757732 \pm 1.0410166$ \\
Protraction & Female & 103 & $36.02 \pm 1.393$ \\
& Male & 97 & $36.08 \pm 1.239$ \\
RHP & Female & 103 & $40.00 \pm 0.543$ \\
\multirow{2}{*}{ Retraction } & Male & 97 & $40.00 \pm 0.641$ \\
& Female & 103 & $42.33 \pm 0.856$ \\
& Male & 97 & $42.04 \pm 0.735$ \\
\hline
\end{tabular}

RHP: Resting head posture, SD: Standard deviation, AP: Anteroposterior

Table 2: Mean and SD values for each outcome measure by gender in Group B

\begin{tabular}{llll}
\hline Parameters & Gender & N & Mean \pm SD \\
\hline Neck length & Female & 103 & $5.415534 \pm 0.6297770$ \\
& Male & 97 & $5.415464 \pm 0.6369426$ \\
AP diameter & Female & 103 & $18.454369 \pm 0.9063801$ \\
& Male & 97 & $18.508247 \pm 1.1329966$ \\
Protraction & Female & 103 & $36.65 \pm 0.977$ \\
& Male & 97 & $36.77 \pm 1.403$ \\
RHP & Female & 103 & $40.00 \pm 0.382$ \\
\multirow{2}{*}{ Retraction } & Male & 97 & $40.00 \pm 0.371$ \\
& Female & 103 & $41.93 \pm 0.744$ \\
& Male & 97 & $41.84 \pm 0.731$ \\
\hline
\end{tabular}

RHP: Resting head posture, SD: Standard deviation, AP: Anteroposterior

\section{DISCUSSION}

In the present era, due to the advancement of technology, today's generation is more prone to musculoskeletal disorders of neck pain

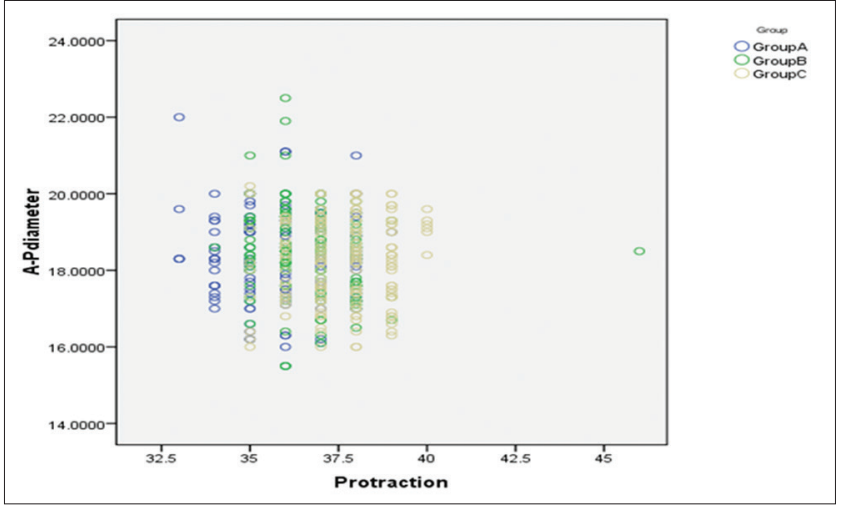

Graph 3: Scatter plot showing Pearson correlation between anteroposterior diameter and protraction

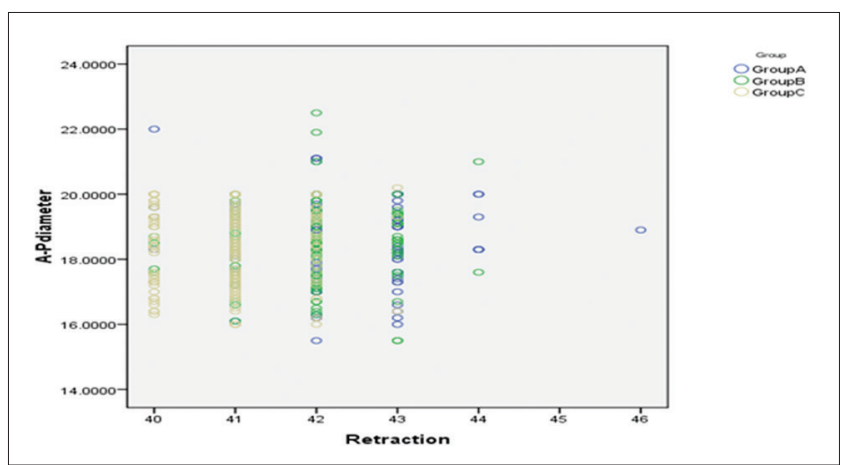

Graph 4: Scatter plot showing Pearson correlation between anteroposterior diameter and retraction

Table 3: Mean and SD values for each outcome measure by gender in Group C

\begin{tabular}{llll}
\hline Parameters & Gender & N & Mean \pm SD \\
\hline Neck length & Female & 103 & $5.386408 \pm 0.6617044$ \\
& Male & 97 & $5.390722 \pm 0.6311502$ \\
AP diameter & Female & 103 & $18.245631 \pm 1.0235249$ \\
& Male & 97 & $18.324742 \pm 1.1096200$ \\
Protraction & Female & 103 & $37.65 \pm 1.177$ \\
& Male & 97 & $37.47 \pm 1.173$ \\
RHP & Female & 103 & $40.00 \pm 0.467$ \\
\multirow{2}{*}{ Retraction } & Male & 97 & $40.00 \pm 0.387$ \\
& Female & 103 & $40.96 \pm 0.670$ \\
& Male & 97 & $40.93 \pm 0.711$ \\
\hline
\end{tabular}

RHP: Resting head posture, SD: Standard deviation, AP: Anteroposterior

as it is one of the most critical area among other musculoskeletal disorders. It is necessary to identify the high-risk individuals. Various anthropometric studies have been conducted on THE of head, but no studies have been conducted on neck length and AP diameter of head on THE of head. Various factors such as age, gender, race, occupation, and nutritional status affect human growth and development. Since different standards are required for different populations [3].

The aim of the present study was to provide the information to clinicians to determine quick and simple methods for quantitative assessment of TNL, AP diameter of head, resting posture of head and THE and preliminary data on head and neck postural measurements for men and women in all age groups. The outcome of the study will also be helpful in providing new information to determine how TNL and AP diameter of head on THE relates to risk for cervical problems in all age groups.

This present study was designed to evaluate the influence of TNL and AP diameter on THE in normal individuals in the age group 8-60 years 
Table 4: Pearson correlation sig (2-tailed) all the Groups - A, B and C: Between neck length, AP diameter, protraction, RHP and retraction

\begin{tabular}{|c|c|c|c|c|c|}
\hline & Neck length & AP diameter & Protraction & RHP & Retraction \\
\hline \multicolumn{6}{|l|}{ Neck length } \\
\hline Pearson correlation & 1 & $0.112^{* *}$ & $-0.151^{* *}$ &.$^{\mathrm{a}}$ & $0.263^{* *}$ \\
\hline Sig. (2-tailed) & & 0.006 & 0.000 & . & 0.000 \\
\hline $\mathrm{N}$ & 600 & 600 & 600 & 600 & 600 \\
\hline \multicolumn{6}{|l|}{ AP diameter } \\
\hline Pearson correlation & $0.112^{* *}$ & 1 & $-0.102^{*}$ &.$^{a}$ & $0.100^{*}$ \\
\hline Sig. (2-tailed) & 0.006 & & 0.012 & . & 0.014 \\
\hline \multicolumn{6}{|l|}{ Protraction } \\
\hline Pearson correlation & $-0.151^{* *}$ & $-0.102^{*}$ & 1 &.$^{a}$ & $-0.520 * *$ \\
\hline Sig. (2-tailed) & 0.000 & 0.012 & & . & 0.000 \\
\hline $\mathrm{N}$ & 600 & 600 & 600 & 600 & 600 \\
\hline \multicolumn{6}{|l|}{ RHP } \\
\hline Pearson correlation &.$^{\mathrm{a}}$ &.$^{\mathrm{a}}$ & $a^{\mathrm{a}}$ &.$^{\mathrm{a}}$ &.$^{a}$ \\
\hline Sig. (2-tailed) & . & . & . & & . \\
\hline $\mathrm{N}$ & 600 & 600 & 600 & 600 & 600 \\
\hline Pearson correlation & $0.263^{* *}$ & $0.100^{*}$ & $-0.520 * *$ &.$^{\mathrm{a}}$ & 1 \\
\hline Sig. (2-tailed) & 0.000 & 0.014 & 0.000 & . & \\
\hline $\mathrm{N}$ & 600 & 600 & 600 & 600 & 600 \\
\hline
\end{tabular}

RHP: Resting head posture, AP: Anteroposterior

and they were divided into three groups according to age and gender: Group A (8-20 years), Group B (21-35 years), and Group C (36-60 years). 200 male and female were represented in each group according to inclusion criteria. The selected parameters of the study were: TNL, AP diameter of head (AP diameter), THE, and RHP.

The finding of the present study identified the significance of TNL and AP diameter of head on THE in all the age categories and genders.

TNL

The result of TNL showed no significant difference between females and males, and there was a positive correlation between neck length and AP diameter of the head. As neck length increases, there is an increase in AP diameter of the head. According to a study conducted by Mahajan et al. (1994), there are no nationwide and global standards for neck length.

A study conducted by Meredith states that for males, head and neck length decreases from $21.4 \%$ of stature at 7 years of age to $18.6 \%$ of stature at 15 and 17 years. For females, there is a similar trend: The decline begins from $20.9 \%$ at 7 years to $18.8 \%$ at 14 years and becomes constant at 14-17 years of age to $18.8 \%$. Head and neck length in percentage of stature is high for males than in females between 7 and 12 years and for females than males between 17 and 17 years of age [13].

A study conducted by Vasavada et al. (2011) states that head and neck anthropometric parameters other than neck length and height was considerably smaller in females compared to males [7].

\section{AP diameter}

The result of AP diameter of the head showed a significant difference in Group A and males compared to females. There is a positive correlation between THE on both neck length and AP diameter of the head. As the head grows through adulthood, the timing of complete closure of site of suture depends upon gender and ethnic group, and the process continues till 50 years of age. In early infancy, skull bones are not fused. The rate of increase in head circumference is $3 \mathrm{~cm}$ per month and fontanelle closes by 9 to 18 months, from $1^{\text {st }}$ year to 20 years there is increase of only $4 "$. A study shows greater the bone mass would be greater the head circumference and increase in height in males [14].

Geraedts et al. conducted a study which showed a significant relation between head circumference in children and young adults. Farkas conducted a study on anthropometry growth study of head and states that length of the head at 1 year of age, showed the highest level of development of head length in both genders compared to adult size. At 5 years of age, the highest level of development among cranial measurement increase in growth was greater between 1 and 5 years than 5 to 18 years of age. Head length in females reached full maturation earliest at the age of 10 years and 4 years later in males. The measurements at maturation time were smaller than 18 years values of male (3.5 mm) and in females (2.2 $\mathrm{mm})$ [15].

Ching (2007) demonstrated in his study that the current analysis of three anthropometric measurements such as head circumference, length, and breadth and by his analysis he stated that head length is not associated with head mass $[16,17]$.

\section{THE}

The result of THE showed a significant difference among three groups, multiple comparisons in both genders and individual male and female groups. Neck length is directly proportional to both retraction and protraction. On correlation with all the groups, there is a negative correlation between protraction and retraction. A study conducted by Hanten et al. demonstrated that males have significant generously proportioned ranges for THE than females. These findings are reliable with studies of mobility in thoracic and lumbar spine which establishes higher values for men than women mainly in sagittal plane.

According to Hayashi along with associates in their study examined radiographic features of cervical spine in 160 ordinary individuals, they found extensive variations in intervertebral motion with greater mobility from $\mathrm{C} 2-\mathrm{C} 3$ to $\mathrm{C} 6-\mathrm{C} 7$ in females. Youdas et al. conducted a study on range of motion on 337 individuals in the age group ranging from 11 to 97 years and found that females had greater range of motion than men except flexion.

Kyalamarkula and Huggares findings in cervical mobility among genders as THE explains that females had more extended head posture than males as evidenced by high mean values for angle among the foramen magnum and posterior to odontoid process as head extends more in cervical spine, the distance between $\mathrm{C} 0$ and $\mathrm{C} 1$ and $\mathrm{C} 2$ reduced in posterior aspect. If women have a reduced amount of upper cervical extension range than men, it would be favorable to imagine THE in females than in males.

Assessment of THE is important in identifying individuals at risk for cervical pathology. Scientific relevance of assessment of spinal mobility has many compensation such as it takes less time, easy to gain 
knowledge, requires minimum tools and has high interstate reliability. This would be a study to determine how THE relates to threat for cervical problems and improvement from them would be interesting follow-up to the current work $[18,19]$.

\section{RHP}

The result of the study shows that there is no significant difference in resting posture of head which is in accordance with study conducted by Hanten et al. (2000) which determined that there is no significant difference attributing to group or gender for RHP in sitting as RHP determines the purposeful amalgamation of THE, which involve flexion and extension of cervical spine $[18,19]$

\section{Limitations}

The present study does not make the difference between normal and patient population.

The present study can be done with larger sample size and for different age groups.

The AP diameter can be differentiated into ratio between the atlantooccipital joint to external occipital protuberance and atlanto-occipital joint to glabella so that the mechanical advantage and disadvantage can be measured which would aid in posture corrections.

\section{CONCLUSION}

The result of the study shows that there is no significant difference in resting posture of the head. In patients with neck pain, THE would be reduced from normal and it depends on neck length and AP diameter of the head. TNL and AP diameter of the head depend on age and gender. Hence, the study concluded that as AP diameter of head decreases there is decrease in neck length and decrease in retraction and increase in protraction or if there is increase in AP diameter and increase in neck length, there is increase in retraction and decrease in protraction.

\section{Future Scope of the Study}

Further studies could determine influence of TNL and AP diameter of head on total head excursion between normal and patient population and compare the influence of neck length and AP diameter of the head in acute and chronic neck pain patients on total head excursion. The study can be done with experimental study design in patient population.

\section{ACKNOWLEDGMENT}

We are thankful to Lovely Professional University, Uni Hospital, Department of Physiotherapy OPD. Phagwara, Punjab and its staff. Out Patient Department of Physiotherapy, Uni Hospital, Lovely Professional University, Phagwara, Punjab, Girls hostels GH- 5, 6a and GH- 6b, Lovely Professional University, Phagwara, Punjab, Vishwakarma Charitable Hospital, Phagwara, Punjab, Government Girls high school, Phagwara, Punjab, Ramgaria Secondary School, Phagwara, Punjab. Villages: Chaheru, Maheru, Nangalmajha, Tanda, Goraya, Hardaspur, Phagwara,
Jalandhar, Punjab for providing input in terms of patient data equipment related to the study.

\section{REFERENCES}

1. Kumar S, Garg R, Mogra K, Choudhary R. Prediction of stature by the measurement of head length in population of Rajasthan. J Evol Med Dent Sci 2013;2(50):2334-9.

2. Hansi B, Ashish B. An estimation of correlation between the head length and the stature of the children aged between 6-10years. Res J Forensic Sci 2015;1(2):1-5.

3. Seema MA. Estimation of personal height from length of head in Punjab zone. Int J Plant Anim Environ Sci 2011;1(3):205-8.

4. Shah GV, Jadhav HR. The study of cephalic index in students of Gujarat. J Anat Soc India 2004;53(1):25-6.

5. Baylis A. Head and Neck Embryology: An Overview of Development, Growth and Defect in Human Fetus. Honours Scholar; 2005. p. 105

6. Antonaci F, Ghirmani S, Nappi G. Currents methods for cervical spine movement evaluation: A review. Clin Exp Rheumatol 2000;18:45-52.

7. Vasavada AN, Daranaj J, Siegmund GP. Female Necks are not Uniformly Scaled Versions of Male Necks. American Society of Biomechanics Annual Conference, San Francisco, CA, August, 22-25; 2007.

8. Hoy DG, Protani M, De R, Buchbinder R. The Epidemiology of Neck. Vol. 24. St. Louis, MO: Elsevier; 2010. p. 783-92.

9. Ailliet L, Rubinstein SM, Knol D, van Tulder MW, de Vet HC Somatisation is associated with worse outcome in a chiropractic patients population with neck pain and low back pain. J Man Ther 2016;21:170-6.

10. Bogduk N. The anatomy and pathophysiology of neck pain. Phys Med Rehabil Clin North Am 2003;4:455-72.

11. Harrison AL, Barry-Greb T, Wojtowicz G. Clinical measurement of head and shoulder posture variables. J Orthop Sports Phys Ther 1996;23(6):353-61.

12. Singla D, Veqar Z. Effect of playing basket ball on the posture of cervical spine in healthy collegiate students. Int J Biomed Adv Res 2015;6(2):133-6

13. Meredith HV. Length of head and neck, trunk and lower extremities on Lowa city children aged seven to seventeen years. Child Dev 1939;10(2):129-44.

14. Menounou A. Head size? Important. Paediatr Neurol 2011;11(2):16-8.

15. Farkas LG, Posnick JL, Hreazko T. Anthropometric growth study of the head. Cleft Palate Craniofac J 1992;29(4):303-8.

16. Ching RP. Relationship Between Head Mass and Circumference in Human Adults. July; 2007. p. 1-5.

17. (a) Pathak KY, Mohanan A, Acharya S, Mandavia D, Jadhav HR. Exploring visceral adiposity index as a predictor of visceral adiposity dysfunction and evaluating its performance in predicting hepatic insulin resistance in Indian Type 2 diabetics. Int J Pharm Pharm Sci 2016;8(8):297-301. (b) Zam W. Vitamin d deficiency and depressive disorders: Review study of probable relationship. Int J Pharm Pharm Sci 2016;8(1):16-22.

18. Hanten WP, Olson SL, Russell JL, Lucio RM, Campbell AH. Total head excursion and resting head posture: Normal and patient comparisons. Arch Phys Med Rehabil 2000;81:62-6.

19. Hanten WP, Russell JL, Lucio RM, Russel JL, Brunt D. Assessment of total head excursion and resting head posture. Arch Phys Med Rehabil 1991;72(11):877-80. 